from the reservoir to enter during only a part of the course of the piston. But the admission of the air ought to vary if it is desired to obtain the same final effect, since the pressure in the reservoir diminishes continuously; and as the apparatus which regulates the admission was arranged to correspond only to determined fractions, but not to vary in a continuous manner, it followed that there was a greater expenditure of air than was necessary, and consequently a diminution in the length of the course over which the locomotive could run.

On the other hand it is necessary that the air should arrive in the distributing apparatus with the least possible pressure, for it is in this apparatus, in the slide-value, that the greatest losses take place, and these losses increase in proportion to the pressure. No means could, however, be thought of for diminishing the pressure in the reservoirs, which would have reduced considerably the work which the machines were capable of doing, unless by augmenting considerably the volume of the reservoirs, the dimensions of which were already unusually large.

At this stage M. Ribourt, the engineer of the tunnel, devised an arrangement which allows the compressed gas to flow at a fixed pressure whatever may be the pressure. in the reservoir. The gas in escaping from the reservoir enters a cylinder $\mathrm{B}$ (Fig. I), over a certain extent of the walls of which are openings $m m$, that communicate with another cylinder $\mathrm{C}$, which surrounds it to the same extent, and which is connected with the slidevalve by which the air is distributed, or, more generally, with the space in which this air is to be utilised. On one side moves a piston $\mathrm{E}$, which shuts the cylinder and hinders the escape of the air. This piston carries externally a shaft $\mathrm{F}$, which supports externally a spiral spring $\mathrm{H}$, the force of which is regulated by means of a screw. Internally it is connected by another shaft $\mathrm{L}$ with a second piston $N$, which bears a cylinder $M$, movable in the interior of the principal pump, and forming thus a sort of internal sheath. This sheath presents openings $n n$, which may coincide exactly with those already referred to, and in that case the gas passes without difficulty from the reservoir at the point where it is to be employed. But if the sheath is displaced, the openings no longer correspond, there is resistance to the passage, and consequently diminution of the quantity of gas which flows out, and hence lowering of pressure in the exterior cylinder. By making the position of the sheath to vary continuously we may make the pressure of exit constant, notwithstanding the continuous variation at entry. But the apparatus is automatic. In fact the part of the cylinder $\mathrm{B}$ comprised between the bottom and the piston $\mathrm{N} \mathrm{C}^{\mathrm{m}} \mathrm{m}-$ municates by openings $p$ (which are never covered with the escape-tube of the gas), in such a manner that upon its posterior face the piston $\mathrm{N}$ receives the pressure of the gas at the moment when it flows, a pressure which it is sought to render constant. The piston $\mathbf{E}$ receives on its anterior face the action of the spring which can be regulated at pleasure. As to the other faces of the two pistons, they are subjected to equal actions proceeding from the pressure of the gas at its entry, actions which thus counteract each other; so that the forces which determine the position of the movable system are on the one hand the tension of the spring, a constant and determined force, and on the other hand, the pressure of the flowing gas; and thus equilibrium cannot occur unless the two forces are equal. If the gas should flow in too great quantity, the pressure increases on the posterior face of the piston $\mathrm{N}$, the spring is overcome, and the movable system advances a little towards the left; but then the orifices are partly covered and the flow diminishes. If the pressure then becomes too weak at the exit, the spring in its turn prevails, pushes the sheath towards the right, uncovers the orifices, and consequently a greater quantity of air may enter.
The machines which are now used at the St. Gothard tunnel, genuine compressed air locomotives, are furnished with M. Ribourt's apparatus. They consist of the following parts:-A sheet-iron reservoir to contain the compressed air is mounted on a framework quite like that of steam locomotives, and carrying glasses, cylinders, distributing apparatus, \&c. The tube for receiving the air possesses, within reach of the driver, the automatic valve of M. Ribourt. The screw being easily regulated, the air can with certainty be made to issue from the apparatus at a determined pressure. This air then passes into a small reservoir (about one-third metre cube) intended to deaden the shocks, which are always produced when the machine is set agoing or stopped. Lastly, this small reservoir communicates with the cylinders, and the air which reaches them acts in the same manner as steam in ordinary locomotives.

-The pressure in the principal reservoir at the point of exit depends on the power of the compressing apparatus; at St. Gothard it may attain 14 kilogrammes per square centimetre, but is ordinarily about 7.35 kilogrammes. The pressure in the small reservoir is arbitrary, depending on the regulation of the screw; at St. Gothard it has a mean of $4^{*} 20$ kilogratrmes. The entire machine weighs about 7 tons.

\section{PHYSICAL SCIENCE IN SCHOOLS}

THE passages from Mr. Wilson's essay of 1867 and his letter of 1876 appeared to me in contradiction on the value of science in developing the power of reasoning and of language, since in his letter Mr. Wilson says that science should not be taught to boys till they have attained a certain power of reasoning and language as shown by their attainments in geometry and Latin; and in his Essay he speaks of science as supplying the want of clearness and certitude better than arithmetic or geometry, and again, as of all processes of reasoning the exhaustive illustration; and I wished to know whether Mr. Wilson had altered his opinion in the last ten years on this point.

The question at issue is as stated: "Given that boys are going to remain under a system of liberal education till eighteen or nineteen, at what stages is it shown by experience that it is wise to introduce the different sciences?". Certainly my experience has not been so extensive as Mr. Wilson's, but I possess the qualification he demands for forming an opinion, that while (during eight years) I have taught science I have also at various times been occupied with mathematics and with language

The extent to which science should be introduced into the curriculum of a particular school, and the order in which the various subjects should be taken up, cannot, I think, be practically determined without taking into account various points of mere expediency. If, for example, expense were no consideration, I should prefer cerain branches of physics, for example, magnetism and electricity, as the subjects for the first practical work to be undertaken rather than chemistry. But practically there is this difference, that a class of twenty or thirty boys in practical chemistry can be handled by one master with fair success; whereas the attempt to carry a class through any such course of physics as that sketched in Weinhold (translated by Foster) could, I think, only end in failure. Two or three boys to whom one master could give his whole attention might use the book with advantage, but a class could not be so handled, except at the additional cost of two or three assistants and considerable time for preparation.

Without, then, asserting that this is the plan theoretically best, we have been led by circumstances at Giggleswick into the following course :-

The school is divided into the upper school, and the lower (or preparatory) school; the upper school consists 
of five classes. No science work (at present) is done in the preparatory school, but all boys in the upper school do some. With the lowest class the subjects are physical geography, and in the summer, botany.

The two reasons why science should be taught in schools are (to quote from Mr. Wilson) that it "is the best teacher of accurate, acute, and exhaustive observation of what is," and that " of all processes of reasoning it stands alone as the exhaustive illustration." And the teaching of physical geography and botany I regard as fulfilling the first of these purposes. We enjoy unusual advantages for the study of these two subjects in the nature of the surrounding country. We are upon the millstone grit, but only a few hundred yards from the great Craven Fault, where the mountain limestone is elevated some 800 feet above the grit into the Giggleswick Scar.

At the distance of a few miles we have the limestone and Yoredale rocks resting unconformably upon the vertical Silurian rocks. Traces of glacial action are numerous-the new line from Settle to Carlisle cuts through moraines, where scratched pebbles may be picked up by the dozen. Erratic blocks are scattered thickly over the whole country. At hand we have the Victoria Cave, and the remains it has yielded are preserved in the school museum, and we are within an aiternoon's ramble of the summits of Ingleborough and Penyghent, and of Clapham Cave, and numerous others. We are equally well off in the matter of botany; a radius of six miles round the school probably includes a greater variety of plants than any equal area in England.

Supposing a boy to enter the upper school at the age of twelve, he would perhaps remain in the class for a year, and at the age of thirteen would enter upon the systematic study of science ; and his first subject would be chemistry, which he would attack at once practically. Four hours a week are given in this class to the study of chemistrya practical lesson of two hours and two oral lessons of an hour each. In the class of perhaps twenty-five, all the boys are making the same experiments at the same time, and the work consists mainly in the study of the properties of the salts of particular metals. The boys are led to infer for themselves from their own experiments the solubility or insolubility of the salts of the metals in water, acids, \&c., and from that to advance to simple analysis. No text-book is used.

In the oral lessons we advance very slowly; one term suffices probably to get through not more than oxygen, bydrogen, and water, and perhaps to begin air. It seems to me that a boy learns much more by understanding thoroughly the experimental evidence that nine pounds of water contain eight pounds of oxygen, than in learning the "mode of preparation and properties" of the oxides of nitrogen and a dozen other substances. In the next class in which the average age is perhaps fourteen to fifteen, we get through nitrogen, carbon, chlorine, bromine, iodine, fluorine, and perhaps sulphur, practical work being continued at the same rate as before. In the second class we have two hours a week for chemistry, two hours for practical work, and two hours for physics. In physics we take the various branches in succession, and get through the subjects of Balfour Stewart's "Physics" in about two years, which is the time many boys remain in the class, the ages being fifteen to seventeen. In the first class we have eight hours a week. The subjects we are taking at present are:-Inorganic and Organic Chemistry, two hours ; Analysis, two hours Electricity and Magnetism, two hours; Astronomy, two hours.

We shall shortly be able, in consequence of the extension of the buildings, to add some practical work in physics. But this will be only for the highest class.

Will you allow me, in conclusion, to quote some of the conclusions of the British Association Committee on Scientific Education in Schools, which appear to me to be still as important as when they were first written The Committee included Mr. Farrar, Prof. Huxley, Prof. Tyndall, and Mr. Wilson:-

"There is an important distinction between scientific information and sciertific training; in other words, between general literary acquaintance with scientific facts, and the knowledge of methods that may be gained by studying the facts at first hand under the guidance of a competent teacher." Both of these are valuable ; it is very desirable, for example, that boys should have some general information about the ordinary phenomena of nature, such as the simple facts of astronomy, of geology, of physical geography, and of elementary physiology. On the other hand, the scientific habit of mind, which is the principal benefit resulting from scientific training, and which is of incalculable value, whatever be the pursuits of after-life, can better be attained by a thorough knowledge of the facts and principles of one science than by a general acquaintance with what has been said and written about many.

"The subjects we recommend for scientific information should comprehend a general description of the solar system, of the form and physical geography of the earth, and of such natural phenomena as tides, currents, winds, and the causes that influence climate, of the broad facts of geology, of elementary natural history with especial reference to the useful plants and animals. And for scientific training we are decidedly of opinion that the subjects which have paramount claims are experimental physics, elementary chemistry, and botany. The science of experimental physics deals with subjects which come within the range of every boy's experience. It embraces the phenomena and laws of light, heat, sound, electricity, and magnetism, the elements of mechanics, and the mechanical properties of liquids and gases. The thorough knowledge of these subjects includes the practical mastery of the apparatus employed in their investigation. The study of experimental physics involves the observation and colligation of facts, and the discovery and application of principies. It is both inductive and deductive. It exercises the attention and the memory, but makes both of them subservient to an intellectual discipline higher than either. The teacher can so present his facts as to make them suggest the principles which underlie them and which once in possession of the principle, the learner may be stimulated to deduce from it results which lie beyond the bounds of his experience. The subsequent verification of his deduction by experiment never fails to excite his interest and awaken his delight.

"Chemistry is remarkable for the comprehensive character of the training which it affords. Not only does it exercise the memory and the reasoning powers, but it also teaches the student to gather by his own experiments and observations the facts upon which to reason.

"Of the value of the elementary teaching in chemistry (at Rugby) there can be only one opinion. It is felt to be a new era in a boy's mental progress when he has realised. the laws that regulate chemical combination and sees traces of order among the seeming endless variety. But. the number of boys who get real hold of chemistry from lectures alonc is smail, as might be expected from the nature of the subject."

Giggleswick, April 15

W. Marshall Watts

We teachers must keep clear in our minds the two sides of the question: the relative educational value of the subject to be taught, and the age or capacity of the pupil. We may roughly classify sciences into those which cultivate the observing, and those which benefit the reasoning powers, though of course all sciences do both. to some extent. Of the former, the only one which should be adopted systematically, in my opinion, is botany. Zoology cannot be as practically taught, though the habits of all kinds of animals afford infinite opportunity 